\title{
Evapotranspiration of an oasis-desert transition zone in the middle stream of Heihe River, Northwest China
}

\author{
LiWen ZHAO ${ }^{1,2}$, WenZhi ZHAO ${ }^{1,2 *}$ \\ ${ }^{1}$ Linze Inland River Basin Research Station, Chinese Ecosystem Network Research, Lanzhou 730000, China; \\ ${ }^{2}$ Key Laboratory of Ecohydrology of Inland River Basin, Cold and Arid Regions Environmental and Engineering Research Institute, \\ Chinese Academy of Sciences, Lanzhou 730000, China
}

\begin{abstract}
As a main component in water balance, evapotranspiration is of great importance for water saving and irrigation-measure making, especially in arid or semiarid regions. Although studies of evapotranspiration have been conducted for a long time, studies concentrated on oasis-desert transition zone are very limited. On the basis of the meteorological data and other parameters (e.g. leaf area index $(L A /)$ ) of an oasis-desert transition zone in the middle stream of Heihe River from 2005 to 2011, this paper calculated both reference $\left(E T_{0}\right)$ and actual evapotranspiration $\left(E T_{\mathrm{c}}\right)$ using FAO56 Penman-Monteith and Penman-Monteith models, respectively. In combination with pan evaporation $\left(E_{\mathrm{p}}\right)$ measured by $E 601$ pan evaporator, four aspects were analyzed: (1) $E T_{0}$ was firstly verified by $E_{\mathrm{p}}$; (2) Characteristics of $E T_{0}$ and $E T_{\mathrm{c}}$ were compared, while the influencing factors were also analyzed; (3) Since meteorological data are often unavailable for estimating $E T_{0}$ through FAO56 Penman-Monteith model in this region, pan evaporation coefficient $\left(K_{\mathrm{p}}\right)$ is very important when using observed $E_{\mathrm{p}}$ to predict $E T_{0}$. Under this circumstance, an empirical formula of $K_{\mathrm{p}}$ was put forward for this region; (4) Crop coefficient $\left(K_{\mathrm{c}}\right)$, an important index to reflect evapotranspiration, was also analyzed. Results show that mean annual values of $E T_{0}$ and $E T_{\mathrm{c}}$ were 840 and 221 $\mathrm{mm}$, respectively. On the daily bases, $E T_{0}$ and $E T_{\mathrm{c}}$ were 2.3 and $0.6 \mathrm{~mm} / \mathrm{d}$, respectively. The annual tendency of $E T_{0}$ and $E T_{\mathrm{c}}$ was very similar, but their amplitude was obviously different. The differences among $E T_{0}$ and $E T_{\mathrm{c}}$ were mainly attributed to the different meteorological variables and leaf area index. The calculated $K_{\mathrm{c}}$ was about 0.25 and showed little variation during the growing season, indicating that available water (e.g. precipitation and irrigation) of about $221 \mathrm{~mm} / \mathrm{a}$ was required to keep the water balance in this region. The results provide an comprehensive analysis of evapotranspiration for an oasis-desert transition zone in the middle stream of Heihe River, which was seldom reported before.
\end{abstract}

Keywords: evapotranspiration; pan evaporation; water requirement; arid region; oasis-desert transition zone

Citation: LiWen ZHAO, WenZhi ZHAO. 2014. Evapotranspiration of an oasis-desert transition zone in the middle stream of Heihe River, Northwest China. Journal of Arid Land, 6(5): 529-539. doi: 10.1007/s40333-014-0061-1

Evapotranspiration $(E T)$ is the total water loss from the earth's surface in the processes of soil evaporation and plant transpiration (Allen et al., 1998; ASCE-EWRI, 2005; Verstraeten et al., 2008). It links the energy and water balances of natural and agricultural ecosystems (Molina et al., 2006), so it is a critical component in water utilization and management, especially in arid regions.

$E T$ is hard to measure directly because it is deter- mined not only by meteorological conditions, plant physiology, soil surface wetness, and soil moisture content, but also by vegetation cover types and the growth stages of plants (Xing et al., 2008). Therefore, various reference terms and models for studying $E T$ have been proposed, developed and implemented during the past 70 years (Penman, 1948; Thornthwaite, 1948; Monteith, 1965; Priestley and Taylor, 1972; Doorenbos and Pruitt, 1977; Shuttleworth and Wallace,

\footnotetext{
"Corresponding author: WenZhi ZHAO (E-mail: zhaowzh@1zb.ac.cn)

Received 2013-09-03; revised 2013-11-23; accepted 2013-12-02

(C) Xinjiang Institute of Ecology and Geography, Chinese Academy of Sciences, Science Press and Springer-Verlag Berlin Heidelberg 2014
} 
1985; Allen et al., 1998; Tasumi et al., 2005). Two reference terms have been developed in previous studies and are now in common use in regard to ET: (1) Reference evapotranspiration, $E T_{0}$, approximates the evapotranspiration rate from dense stands of actively growing, well-watered, green grass of uniform height, where these completely cover the ground and block sunlight from reaching the surface (Doorenbos and Pruitt, 1984; Allen et al., 1998; ASCE-EWRI, 2005); (2) Actual evapotranspiration, $E T_{\mathrm{c}}$, refers to all the processes that transform liquid water at or near the land surface into vapor, under cultivated or natural conditions (Jensen et al., 1990; Allen et al., 1994; Jensen et al., 1997; Allen et al., 1998; Allen et al., 2011). Although $E T_{0}$ and $E T_{\mathrm{c}}$ are different terms, both of them play a crucial role in understanding the heat and mass flux in the atmospheric system as well as in hydrological regimes (Ehlers and Krafft, 1996). It is worth mentioning that the ratio of $E T_{\mathrm{c}}$ to $E T_{0}$, is defined in the FAO56 as the crop coefficient $\left(K_{\mathrm{c}}\right)$ that plays an essential part in calculations and theoretical analyses (Allen et al., 1998).

The arid inland area of Northwest China consists of various inland river basins, where the very limited water resources are concentrated in oases. At present, many oases have been degenerating into deserts due to the over-exploitation of water resources in these regions ( $\mathrm{Su}$ et al., 2007). The Linze Oasis is one of these-a typical artificial and agricultural oasis in the middle stream of the Heihe River. With an average annual precipitation of about $117 \mathrm{~mm}$ ( $\mathrm{Li}$ and Zhao, 2010), the continued existence of the oasis is mainly dependent on irrigation, and the desert and oasis interact in the process of desertification. Land desertification has increased mainly in the oasis-desert transition zone, which occupies $18.9 \%$ of the middle reach of the Heihe River (Zhou and Yang, 2006). Therefore, ecosystem stability in the oasis-desert transition zone is critical for sustainable economic growth in this region. Any improvement in the water budget will be of great benefit to both hydrologic processes and the local population. Such benefits require an accurate assessment of the water budget for the oasis-desert transition zone, and $E T$ is the key factor affecting water loss in this budget.

Over the past several decades, in this arid region, researchers have concentrated on the ET of oases or deserts with various observational systems and models for various plants (Wu et al., 2005; Li and Zhao, 2010; Liu et al., 2010; Zhao et al., 2010a, b; Zhao and Ji, 2010; Li et al., 2011). They have found that during the growing season the annual $E T_{\mathrm{c}}$ of farmland oases ranged from 552 to $777 \mathrm{~mm}$, and that of deserts from 144 to $292 \mathrm{~mm}$. With respect to the oasis-desert transition zone, Jia et al. (2012) studied the instantaneous variation of ET basing on the SEBLE model. Little work about $E T$ has been done in the oasis-desert transition zone. But there is an urgent need to do so, given the seriously increasing desertification.

In this study, 7 years of experimental data were collected in the oasis-desert transition zone in the middle stream of Heihe River, Northwest China. Both $E T_{0}$ and $E T_{\mathrm{c}}$ were then calculated using the FAO56 Penman-Monteith and the Penman-Monteith model at daily time steps. $K_{\mathrm{c}}$ was then obtained according to the calculated $E T_{0}$ and $E T_{\mathrm{c}}$ during the growing season. Because of the lack of sufficient meteorological data, $E T_{0}$ during the growing season was calculated in combination with the $E_{\mathrm{p}}$ (pan evaporation) and $K_{\mathrm{p}}$ (pan evaporation coefficient). The results of this study will help to establish a theoretical and practical foundation for water resource management and effective maintenance of the ecosystem in an oasis-desert transition zone in the middle stream of Heihe River.

\section{Study area and data analysis}

\subsection{Study area}

The study area is located in an oasis-desert transition zone in the middle stream of Heihe River, as shown in Fig. 1, which shows the interface between the Badain Jaran Desert and the Zhangye Oasis. The mean annual precipitation is about $118 \mathrm{~mm}(1965-2010)$, the annual mean temperature about $7.6^{\circ} \mathrm{C}$, the dryness index about 15.9, and the potential evaporation about 2,366 $\mathrm{mm} / \mathrm{a}$ (Liu et al., 2010). The study area was part of a sandstorm-eroded area, and was converted into an artificial oasis in the 1970s. At present, the soil is sandy, and several sand-fixation plant species have been planted there, such as Haloxylon ammodendron, Elaeagnus angustifolia, Tamarix ramosissima, $\mathrm{Ni}$ traria sphaerocarpa, and annual herbaceous species such as Bassia dasyphylla, Halogeton arachnoideus, Suaeda glauca and Agriophyllum squarrosum. The 
vegetation cover is about $6 \%$, with a plant growing period of April-October. However, only a few kinds of plants can survive in this area with the severe ecological conditions of low precipitation and intense evaporation.

\subsection{Observational measurements}

\subsubsection{Meteorological data}

A comprehensive weather station was set up at the oasis-desert transition zone in 2004, at Pingchuan town, which is a part of the Chinese Ecosystem Research Network (CERN). Many meteorological parameters have been under long-term monitoring with different instruments, as shown in Table 1. As for the monitoring intervals, wind speed and direction were monitored once every two minutes, sense precipitation was measured three times a day $(8: 00,14: 00$ and 20:00), and other parameters were obtained once an hour. With respect to mean daily values, precipitation and sense precipitation were obtained by accumulating the observed values in one day, while others were the average values during one day. Some of the monitored data, gathered from 2005 through 2011, were used in this paper.

\subsubsection{Pan evaporation}

Surface water evaporation was measured by an E601 evaporator (modified from GGI-3000, China). The

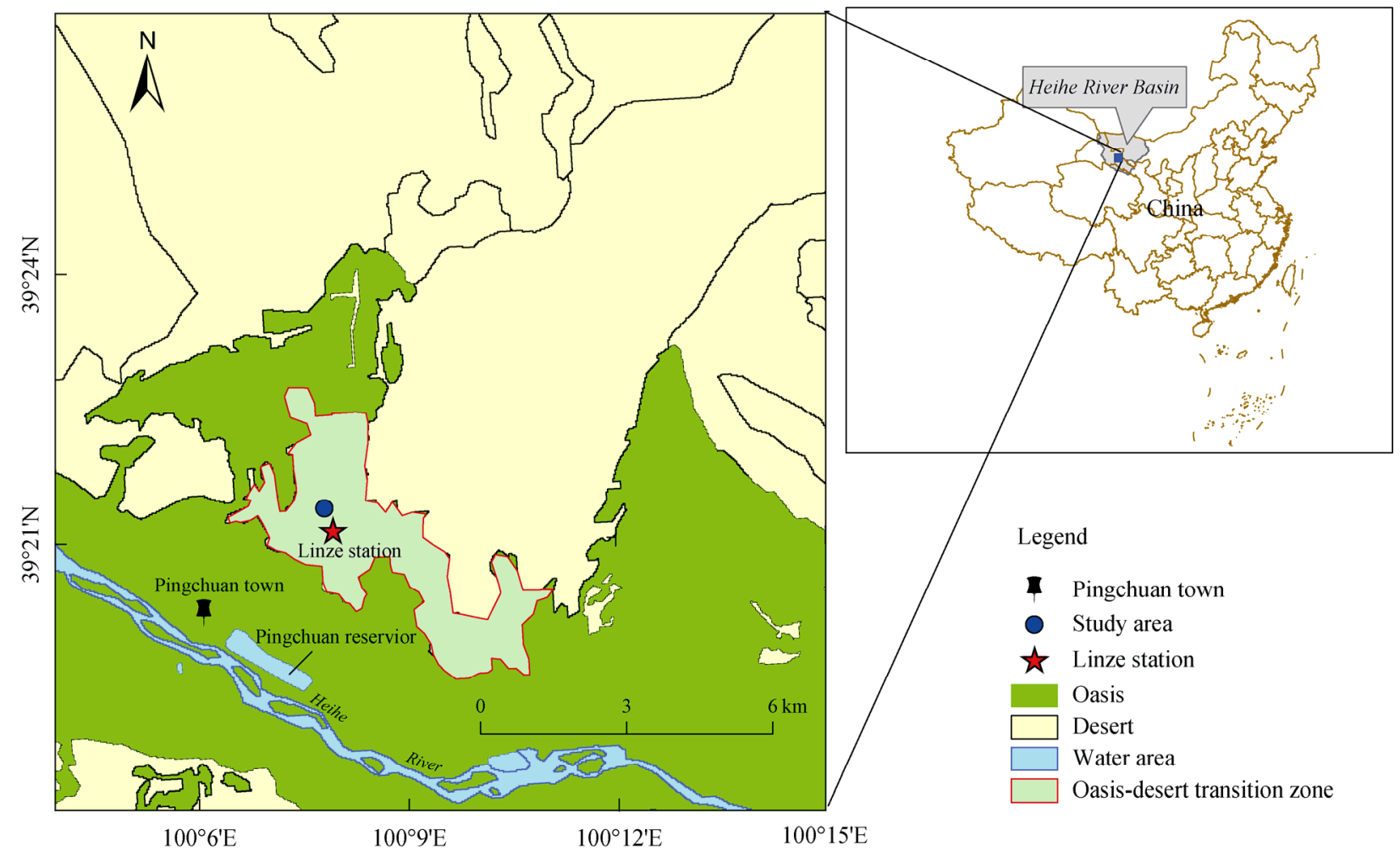

Fig. 1 Geographical location of the study area

Table 1 Some of the meteorological parameters observed at the weather station

\begin{tabular}{llcllc}
\hline Parameter & Instrument & Observational elevation & Parameter & Instrument & Observational elevation \\
\hline Pressure & DPA501 & $70 \mathrm{~cm}$ & Total radiation & CM11 & $2 \mathrm{~m}$ \\
Air temperature & HMP45D & $2 \mathrm{~m}$ & Reflected radiation & CM6B & $2 \mathrm{~m}$ \\
Humidity & HMP45D & $2 \mathrm{~m}$ & Net radiation & QMN101 & $2 \mathrm{~m}$ \\
Wind direction & WAV151 & 2 and $10 \mathrm{~m}$ & Photosynthetic radiation & LI-190SZ & $2 \mathrm{~m}$ \\
Wind speed & WAA151 & 2 and $10 \mathrm{~m}$ & UV radiation & CUV3 & $2 \mathrm{~m}$ \\
Soil temperature & QMT110 & $0,-5,-10,-15,-20,-40,-60$ and $-100 \mathrm{~cm}$ & Soil heat flux & HFP01SC & $5 \mathrm{~cm}$ \\
Precipitation & RG13H & $70 \mathrm{~cm}$ & Sense precipitation & DRD11A & $2 \mathrm{~m}$ \\
\hline
\end{tabular}

Note: For the observational elevation, positive and negative values denote the height above ground surface and the depth below ground surface, respectively. 
water levels were monitored twice a day (8:00 and 20:00) only in the growing season (from 20 April to 15 October) during the seven years from 2005 to 2011.

The mean daily evaporation was calculated using the following equation:

$$
E_{\mathrm{p}}=P+\left(n_{1}-n_{2}\right) .
$$

Where, $E_{\mathrm{p}}$ is the mean daily pan evaporation $(\mathrm{mm} / \mathrm{d})$; $P$ is the mean daily precipitation; and $n_{1}$ and $n_{2}$ are water surface heights measured in the evaporators for the previous and present measurements, respectively.

\subsubsection{Others}

Leaf area index $\left(L A I, \mathrm{~m}^{2} / \mathrm{m}^{2}\right)$ was measured using LI-3100A area meter (LI-COR, Inc., Lincoln, NE) every month from May to September. Twenty quadrats were randomly chosen in the study area, and leaf area of each species was measured based on the vegetation coverage. The arithmetic mean of observation values was taken as the leaf area index.

\subsection{Calculation methods}

\subsubsection{FAO56 Penman-Monteith model $\left(E T_{0}\right)$}

The FAO56 Penman-Monteith model (Allen et al., 1998) for calculating the hypothetical reference evapotranspiration is considered to be the most reasonable model, as follows:

$$
E T_{0}=\frac{0.408 \Delta\left(R_{\mathrm{n}}-G\right)+\gamma \frac{900}{T+273} u_{2}\left(e_{\mathrm{s}}-e_{\mathrm{a}}\right)}{\Delta+\gamma\left(1+0.34 u_{2}\right)} .
$$

Where, $E T_{0}$ is the reference evapotranspiration $(\mathrm{mm} / \mathrm{d}) ; R_{\mathrm{n}}$ is the net radiation $\mathrm{MJ} /\left(\mathrm{m}^{2} \cdot \mathrm{d}\right) ; G$ is the soil heat flux $\mathrm{MJ} /\left(\mathrm{m}^{2} \cdot \mathrm{d}\right) ; \Delta$ is the slope of the vapor pressure versus temperature curve $\left(\mathrm{kPa} /{ }^{\circ} \mathrm{C}\right) ; T$ is mean daily temperature at $2 \mathrm{~m}$ above the ground surface $\left({ }^{\circ} \mathrm{C}\right) ; u_{2}$ is the wind speed at $2 \mathrm{~m}$ above the ground surface $(\mathrm{m} / \mathrm{s}) ; e_{\mathrm{s}}$ is the saturation vapor pressure $(\mathrm{kPa})$; $e_{\mathrm{a}}$ is the actual vapor pressure $(\mathrm{kPa})$; and $r$ is the psychrometric constant $\left(\mathrm{kPa} /{ }^{\circ} \mathrm{C}\right)$.

\subsubsection{Penman-Monteith model $\left(E T_{\mathrm{c}}\right)$}

The physically-based Penman-Monteith (P-M) model (Monteith, 1965) was used to calculate the actual evaportranspiration, as follows:

$$
E T_{\mathrm{c}}=\frac{\Delta\left(R_{\mathrm{n}}-G\right)+\rho C_{\mathrm{p}}\left(e_{\mathrm{s}}-e_{\mathrm{a}}\right) / r_{\mathrm{a}}}{\Delta+\gamma\left(1+r_{\mathrm{s}}\right) / r_{\mathrm{a}}} .
$$

Where, $E T_{\mathrm{c}}$ is the actual evapotranspiration $(\mathrm{mm} / \mathrm{d}) ; r_{\mathrm{s}}$ is the bulk surface resistance $(\mathrm{s} / \mathrm{m}) ; r_{\mathrm{a}}$ is the aerodynamic resistance $(\mathrm{s} / \mathrm{m}) ; \rho$ is the air density $\left(\mathrm{kg} / \mathrm{m}^{3}\right)$; and $C_{\mathrm{p}}$ is the specific heat of air $\left(\mathrm{MJ} /\left(\mathrm{kg} \cdot{ }^{\circ} \mathrm{C}\right)\right)$. Other variables have been defined in the above section.

The aerodynamic resistance can be obtained from Pereira's equation (Pereira et al., 1999), which varies between the top of the crop plants and the reference point sited in the boundary layer above the canopy assuming neutral conditions, by the following formula:

$$
r_{\mathrm{a}}=\frac{\ln \left[(z-d) / z_{0}\right] \times \ln [(z-d) /(h-d)]}{k^{2}} \times \frac{1}{u} .
$$

Where, $z$ is the reference level where the horizontal wind speed is measured $(\mathrm{m}) ; d$ is the zero plane displacement height $(\mathrm{m}) ; z_{0}$ is the roughness length for momentum (m); $h$ is the height of the crop (m); $k$ is the von Karman's constant with a value of 0.41 here; $d=0.67 \mathrm{~h}$ and $z_{0}=0.123 \mathrm{~h}$.

The bulk canopy resistance $\left(r_{\mathrm{c}}\right)$ was determined by the mean daily stomatal resistance of the single leaves $\left(r_{\mathrm{s}}\right)$ and the leaf area index of those leaves in effective transpiration $\left(L_{\text {eff }}\right)$ (Szeicz and Long, 1969). The resistance was then used to caculate the reference evapotranspiration (Allen et al., 1998) or to estimate the actual evapotranspiration (Steiner et al., 1991; Stannard, 1993; Howell et al., 1995):

$$
r_{\mathrm{c}}=r_{\mathrm{s}} / L_{\text {eff }} \text {. }
$$

Since the mean stomatal resistance of single leaves cannot be measured directly due to the diversity of the vegetation, a value of $200 \mathrm{~s} / \mathrm{m}$ was adopted for the oasis-desert transition zone based on prior works (Stannard, 1993; Allen et al., 1998; Liu and Zhao, 2009; Gao et al., 2010).

\section{Results}

\subsection{Meteorological data}

Figure 2 shows some of the meteorological data of the study area. A mean daily value was calculated in different months to illustrate the variation characteristics for net radiation $\left(R_{\mathrm{n}}\right)$, air temperature $(T)$, relative humility $(R H)$ and wind speed $\left(u_{2}\right)$, while the precipitation $(P)$ values were the accumulated monthly values. Slight changes can be seen for all five of the parameters in different years. The mean daily value of $R_{\mathrm{n}}, T$, 
$R H$, and $u_{2}$ were about $4.5 \mathrm{MJ} /\left(\mathrm{m}^{2} \cdot \mathrm{d}\right), 9.0^{\circ} \mathrm{C}, 45 \%$ and $1.8 \mathrm{~m} / \mathrm{s}$, respectively. The variation characteristics of $R_{\mathrm{n}}$ and $T$ were similar. Both of them reached the maximum values near June and the minimum values near December. $R H$ reached the maximum value of about $75 \%$ around the time of the coldest air temperature (December). $u_{2}$ reached the maximum values near March and the minimum values near December. As for $P$, the mean annual value was about $129 \mathrm{~mm}$, with the maximum monthly value in around October. The variation characteristics of the meteorological param- eters were assumed to have certain influences on evapotranspiration.

\subsection{Reference and actual evapotranspiration}

Figure 3 shows the reference evapotranspiration $\left(E T_{0}\right)$ and actual evapotranspiration $\left(E T_{\mathrm{c}}\right)$ at the oasis-desert transition zone calculated by Eqs. 2 and 3, respectively, in combination with the meteorological data (Fig. 2). The maximum values appeared in around July and the minimum values in around January each year for the two types of evapotranspira-
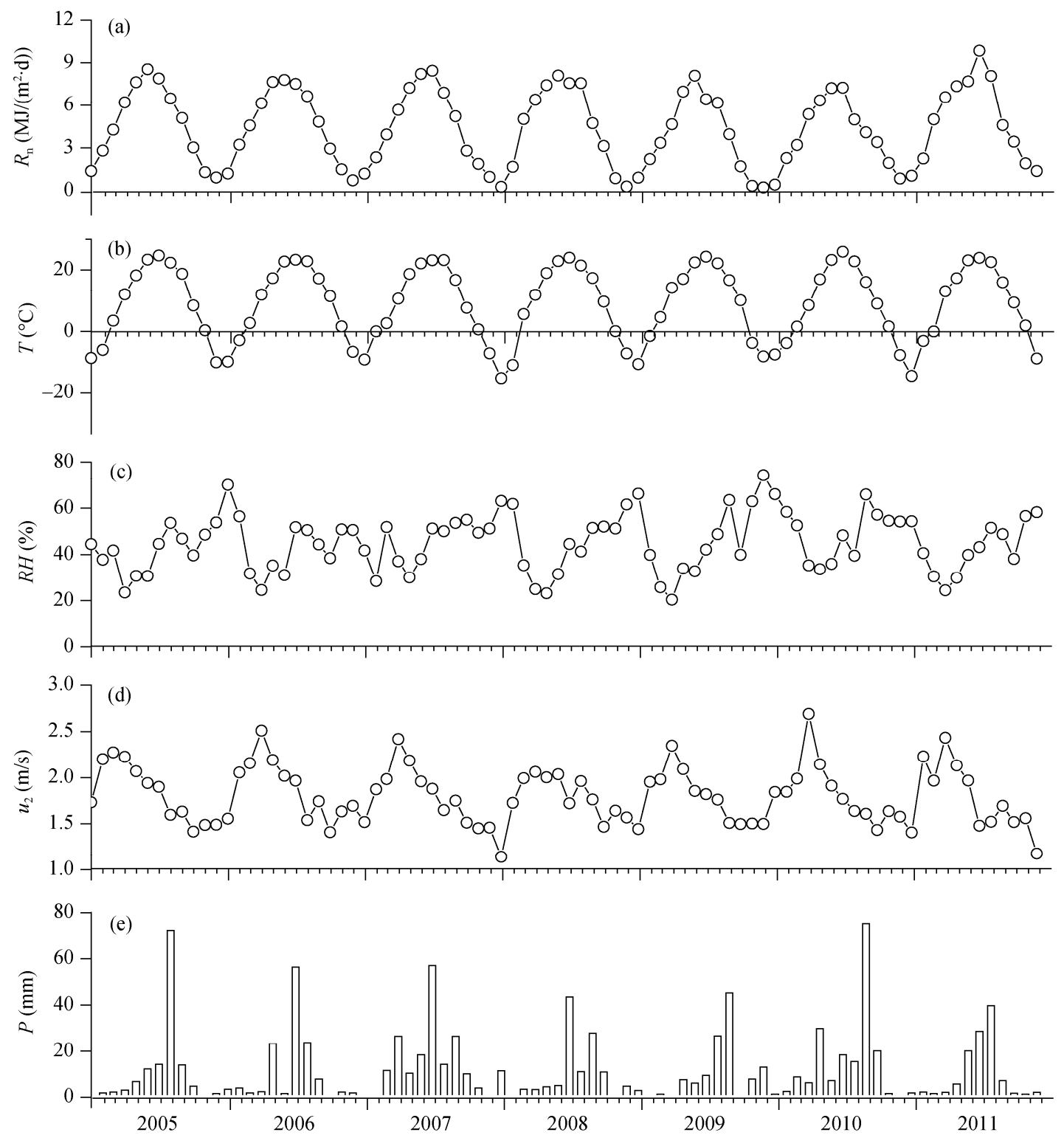

Fig. 2 The selected meteorological parameters: $R_{\mathrm{n}}$, net radiation (a); $T$, air temperature at $2 \mathrm{~m}$ above the ground surface (b); $R H$, relative humidity (c); $u_{2}$, wind speed at $2 \mathrm{~m}$ above the ground surface (d); $P$, precipitation (e) 


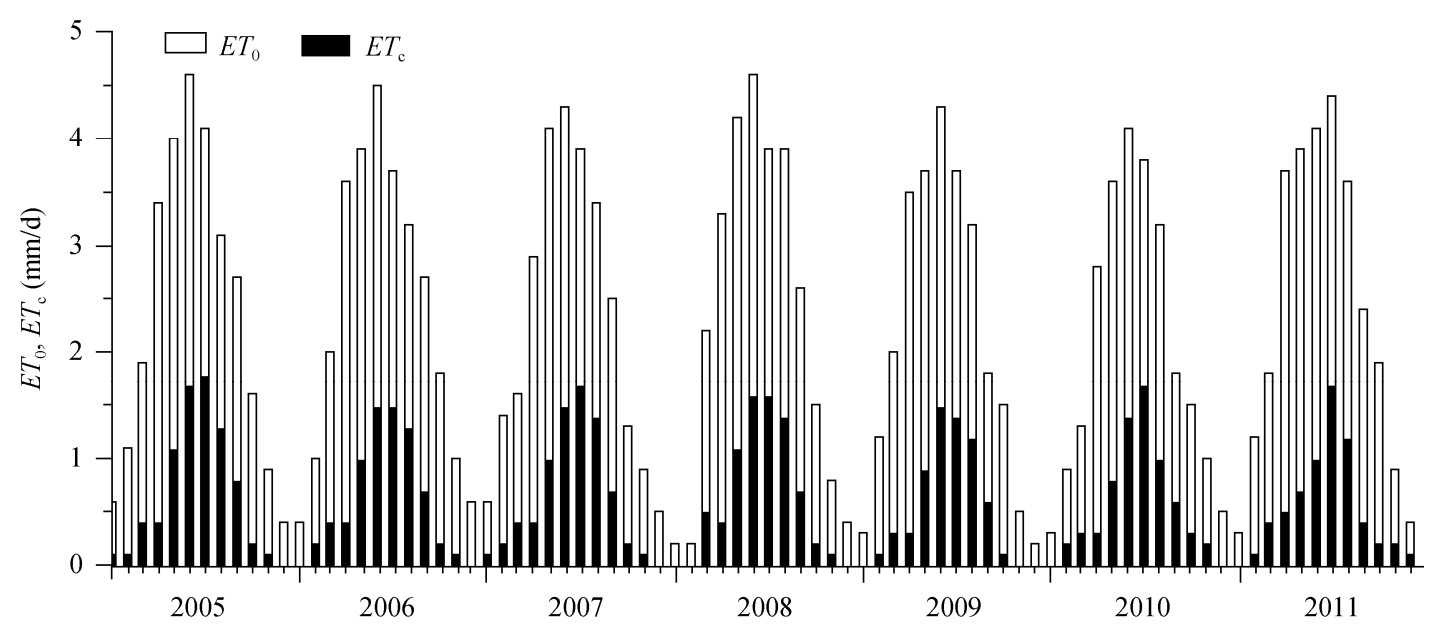

Fig. 3 Variation of monthly $E T_{0}$ and $E T_{\mathrm{c}}$ from 2005 to 2011

tion, and the distributions were similar to the normal distribution. Of note is that the variation of evaporation was closely related to the radiation (Fig. 2a) and air temperature (Fig. 2b). The range of $E T_{0}$ was from $763-878 \mathrm{~mm} / \mathrm{a}$, with an average of 840 $\mathrm{mm} / \mathrm{a}$, while $E T_{\mathrm{c}}$ from $197-242 \mathrm{~mm} / \mathrm{a}$, with an average of $221 \mathrm{~mm} / \mathrm{a}$. On the daily bases, $E T_{0}$ and $E T_{\mathrm{c}}$ were 2.3 and $0.6 \mathrm{~mm} / \mathrm{d}$, respectively.

\section{Discussion}

\subsection{Validation of $E T_{0}$ by $E_{\mathrm{p}}$}

$E_{\mathrm{p}}$ is a good indication of terrestrial evaporation component in hydrologic cycle (Brutsaert and Parlange, 1998), and it has been used to validate $E T_{0}$ (Zhang et al., 2007). The similar spatial distrubtions of $E_{\mathrm{p}}$ and $E T_{0}$ were also investigated (Xu et al., 2006). In this paper, $E_{\mathrm{p}}$ were obtained from the E601 evaporator, which has a stable conversion coefficient with the Class-A evaporator ( $\mathrm{Fu}$ et al., 2004), resulting a credible value of $E_{\mathrm{p}}$. Previous study also showed that there was a satisfactory correlation between Class-A pan data and calculated $E T_{0}$ (Chiew et al., 1995).

Figure 4 shows a relatively high correlation between $E_{\mathrm{p}}$ and $E T_{0}\left(R^{2}=0.68, P<0.001\right)$. Though there were deviations among $E_{\mathrm{p}}$ and $E T_{0}$, the figure still implied that FAO56 Penman-Monteith model can be selected to obtain credible values of $E T_{0}$.

\subsection{Comparison between $E T_{0}$ and $E T_{\mathrm{c}}$}

The study area is a typical oasis-desert transition zone in an arid region with climatic characteristics similar to the Sahara Desert (Fisher et al., 2011)-very hot, windy and dry. From Fig. 3, it can be seen that the value of $E T_{0}$ was about $74 \%$ larger than $E T_{\mathrm{c}}$ during years from 2005 to 2011 . As for seasonal variation, the proportions of $E T_{0}$ during spring, summer, autumn and winter to the entire year were $33 \%, 43 \%, 17 \%$ and $7 \%$, respectively, while the proportions of $E T_{\mathrm{c}}$ were $24 \%, 60 \%, 13 \%$ and $3 \%$, respectively (Fig. $5 a$ ). In summer, the relatively higher values of $E T_{0}$ and $E T_{\mathrm{c}}$ compared to the other three seasons were probably caused by the high air temperature and low precipitation, and the relatively higher values of $E T_{\mathrm{c}}$ compared to $E T_{0}$ were probably due to high plant transpiration. In addition, annual $E T_{\mathrm{c}}$ accounted for only $28 \%, 27 \%, 28 \%, 27 \%, 25 \%, 27 \%$ and $22 \%$ of $E T_{0}$ during the years 2005-2011. The main reason for these low values is that solar radiation, air humidity and wind speed are the main climate-influencing factors for $E T_{0}$ (Monteith, 1981; Raupach, 2001),

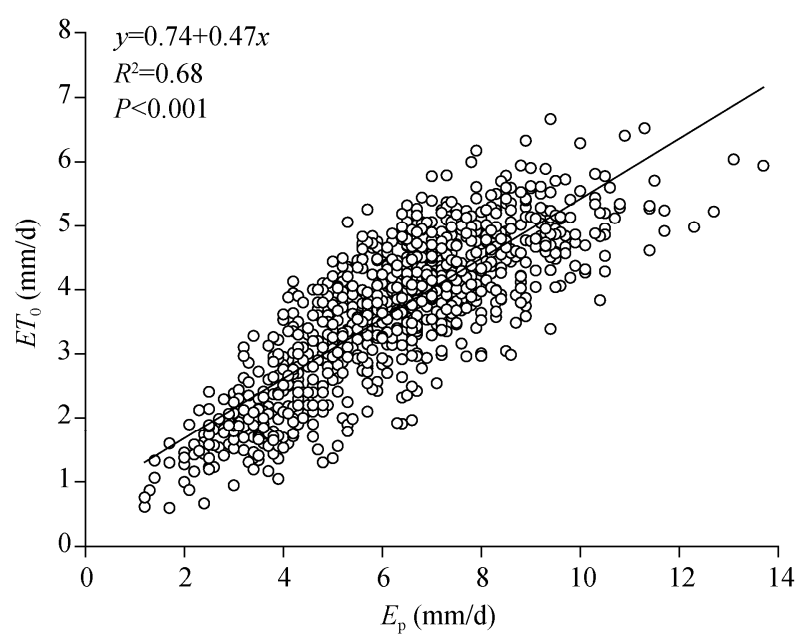

Fig. 4 Relationship between $E T_{0}$ and $E_{\mathrm{p}}$ 
while $E T_{\mathrm{c}}$ was controlled not only by the above three factors but also by vegetation, including leaf and canopy characteristics, regulation of stomata and rooting dynamics (Allen et al., 1998).

Regression analysis between $E T_{0}$ and $E T_{\mathrm{c}}$ shows a similar trend during the recording period (Fig. 5b), which may be attributed to the similar main influencing factors among them. In conbination with section 3.1, the figure also implied that Penman-Monteith model can be selected to obtain credible values of $E T_{\mathrm{c}}$, to some extent. For under-

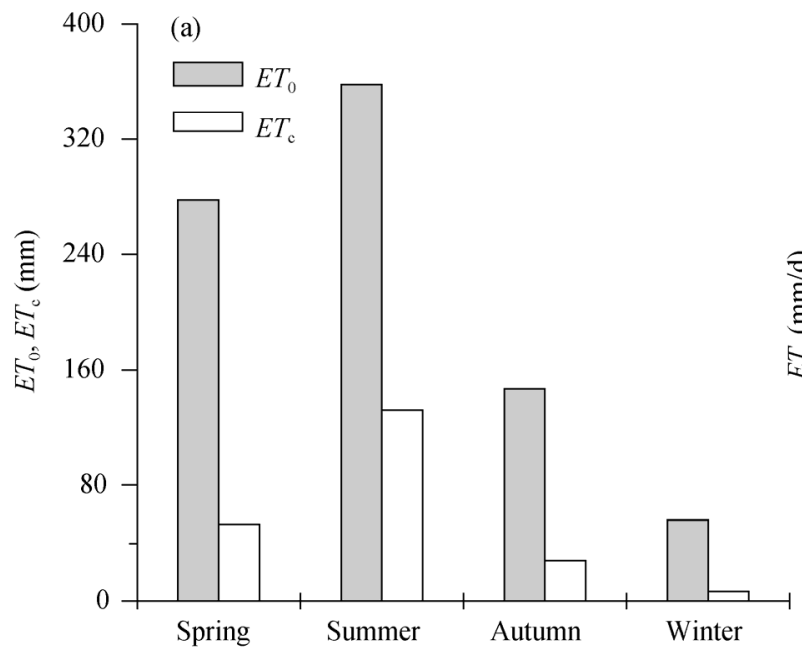

standing the influence of the main meteorological characteristics on the variables of $E T_{0}$ and $E T_{\mathrm{c}}$, a partial correlation analysis was performed (De La Fuente et al., 2004), as shown in Tables 2 and 3. It can be seen that $E T_{0}$ increased with the increase of net radiation and air temperature, but decreased with an increase in the wind speed. $E T_{\mathrm{c}}$ increased with an increase in net radiation, air temperature and leaf area index, but decreased with an increase in relative humity. In addition, wind speed shows little effect on $E T_{\mathrm{c}}$. This indicates that the two main influencing

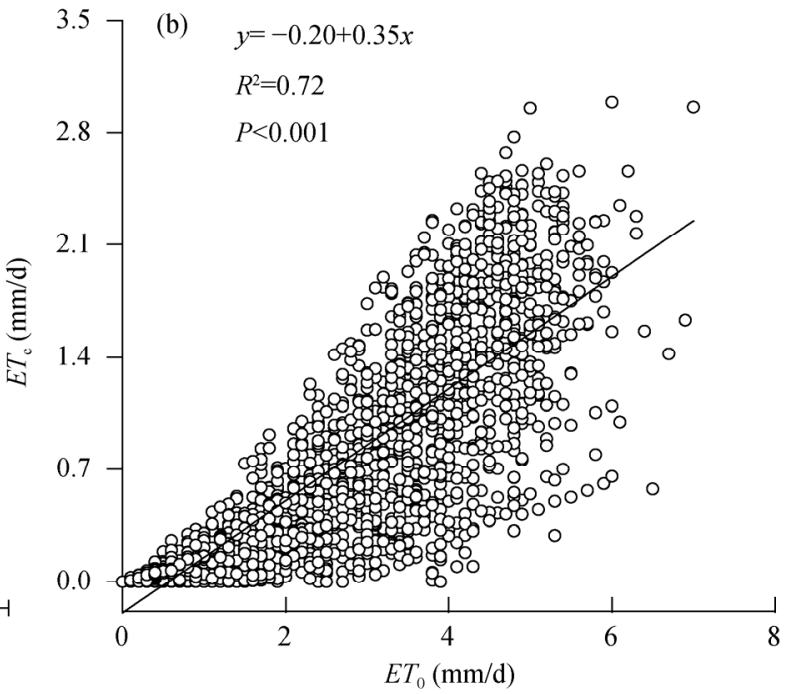

Fig. $5 E T_{0}$ and $E T_{c}$ in different seasons (a) and regression analysis between them (b)

Table 2 The partial coefficients between modeled $E T_{0}$ and environmental factors of correlation analysis

\begin{tabular}{lccccc}
\hline & $E T_{0}$ & $R_{\mathrm{n}}$ & $T$ & $R H$ & $u_{2}$ \\
\hline$E T_{0}$ & 1 & $0.872^{* *}$ & $0.858^{* *}$ & $-0.615^{* *}$ & $0.314^{* *}$ \\
$R_{\mathrm{n}}$ & & 1 & $0.739^{* *}$ & $-0.446^{* *}$ & $0.090^{* *}$ \\
$T$ & & 1 & $-0.408^{* *}$ & $0.138^{* *}$ \\
$R H$ & & & 1 & $-0.222^{* *}$ \\
$u_{2}$ & & & & 1 \\
\hline
\end{tabular}

Note: * denotes partial regression analysis at the $5 \%$ level of significance; $* *$ denotes partial regression analysis at the $1 \%$ level of significance.

Table 3 The partial coefficients between modeled $E T_{\mathrm{c}}$ and environmental factors of correlation analysis

\begin{tabular}{lcccccc}
\hline & $E T_{\mathrm{c}}$ & $L A I$ & $R_{\mathrm{n}}$ & $T$ & $R H$ & $u_{2}$ \\
\hline$E T_{\mathrm{c}}$ & 1 & $0.863^{* *}$ & $0.848^{* *}$ & $0.783^{* *}$ & $-0.272^{* *}$ & $-0.030^{* *}$ \\
$L A I$ & & 1 & $0.649^{* *}$ & $0.850^{* *}$ & $-0.132^{* *}$ & $0.049^{*}$ \\
$R_{\mathrm{n}}$ & & 1 & $0.739^{* *}$ & $-0.445^{* *}$ & $0.089^{* *}$ \\
$T$ & & & 1 & $-0.407^{* *}$ & $0.137^{* *}$ \\
$R H$ & & & & 1 & $-0.222^{* *}$ \\
$u_{2}$ & & & & & 1 \\
\hline
\end{tabular}

Note: * denotes partial regression analysis at the $5 \%$ level of significance; $* *$ denotes partial regression analysis at the $1 \%$ level of significance. 
factors are similar for $E T_{0}$ and $E T_{\mathrm{c}}$ : net radiation and air temperature. In addition, leaf area index is another important influence factor for $E T_{\mathrm{c}}$.

\subsection{Crop coefficient}

Crop coefficient $\left(K_{\mathrm{c}}\right)$ is defined as the ratio of $E T_{\mathrm{c}}$ to $E T_{0}$, which is controlled by various factors: crop variety, irrigation regime, weather, soil type, field management and so on. In combination with $E T_{0}, K_{\mathrm{c}}$ was used to estimate $E T_{\mathrm{c}}$ (Jensen, 1974; Allen et al., 1998). Quantification and characterization of $K_{\mathrm{c}}$ populations for various crops in a region would be valuable in defining average water use by crop type under field conditions and the range of water use (Tasumi et al., 2005). In this study, the calculated $E T_{0}$ and $E T_{\mathrm{c}}$ were applied to determine an actual $K_{\mathrm{c}}$ for the study area with various vegetation types.

Figure 6 shows the average monthly variation of $K_{\mathrm{c}}$ during the plant growing season. It can be seen that $K_{\mathrm{c}}$ varied between 0.1 and 0.5 , with an average value of about 0.25 , and reached its maximum value in around July. Although changes can be seen for meteorological parameters, especially precipitation (Fig. 2), $K_{\mathrm{c}}$ showed little variation, indicating that the study area was a balanced ecosystem during the recording period. Considering that the mean annual $E T_{\mathrm{c}}$ was about $221 \mathrm{~mm}$, it can be suggested that available water (e.g. precipitation and dew) of about $221 \mathrm{~mm}$ can maintain the water balance in the oasis-desert transition zone in arid regions of Northwest China.

\subsection{Pan evaporation coefficient}

When lacking full climatic data, $E T_{0}$ can be estimated from easily observed $E_{\mathrm{p}}$ and just a few climate data (Snyder et al., 2005; Li et al., 2010), which was also suggested by Allen et al. (1998). Under this circumstance, $K_{\mathrm{p}}$ is of great importance, and the simple equation was proposed by Doorenbos and Pruitt (1977 and 1984), as follows:

$$
K_{\mathrm{p}}=E T_{0} / E_{\mathrm{p}} .
$$

The mean value of $K_{\mathrm{p}}$ is thought to be about 0.70 in semi-arid environments (Jensen et al., 1990) and about 0.80 in arid environments (Rana and Katerji, 2000).

The $K_{\mathrm{p}}$ in the plant-growing season from April to October is the emphasis in this paper. The mean daily values of $E_{\mathrm{p}}$ are from 0.3 to $13.7 \mathrm{~mm} / \mathrm{d}$, with an average of $5.9 \mathrm{~mm} / \mathrm{d}$ during the growing season. It reached the maximum values in around July (Fig. 7a), which was probably caused by the relatively high radiation and air temperature.

According to Eq. $6, K_{\mathrm{p}}$ can be easily obtained using $E_{\mathrm{p}}$ (Fig. 7a) and $E T_{0}$ (Fig. 3). It is noted that $K_{\mathrm{p}}$ fluctuated within the range of $0.20-0.98$, with an average of 0.75 during the growing season, which was in good agreement with the results of Jensen and Rana (Jensen et al., 1990; Rana and Katerji, 2000). On the other hand, a simpler way (i.e. Snyder equation) to obtain $K_{\mathrm{p}}$ using three important meteorological parameters (Doorenbos and Pruitt, 1977; Doorenbos

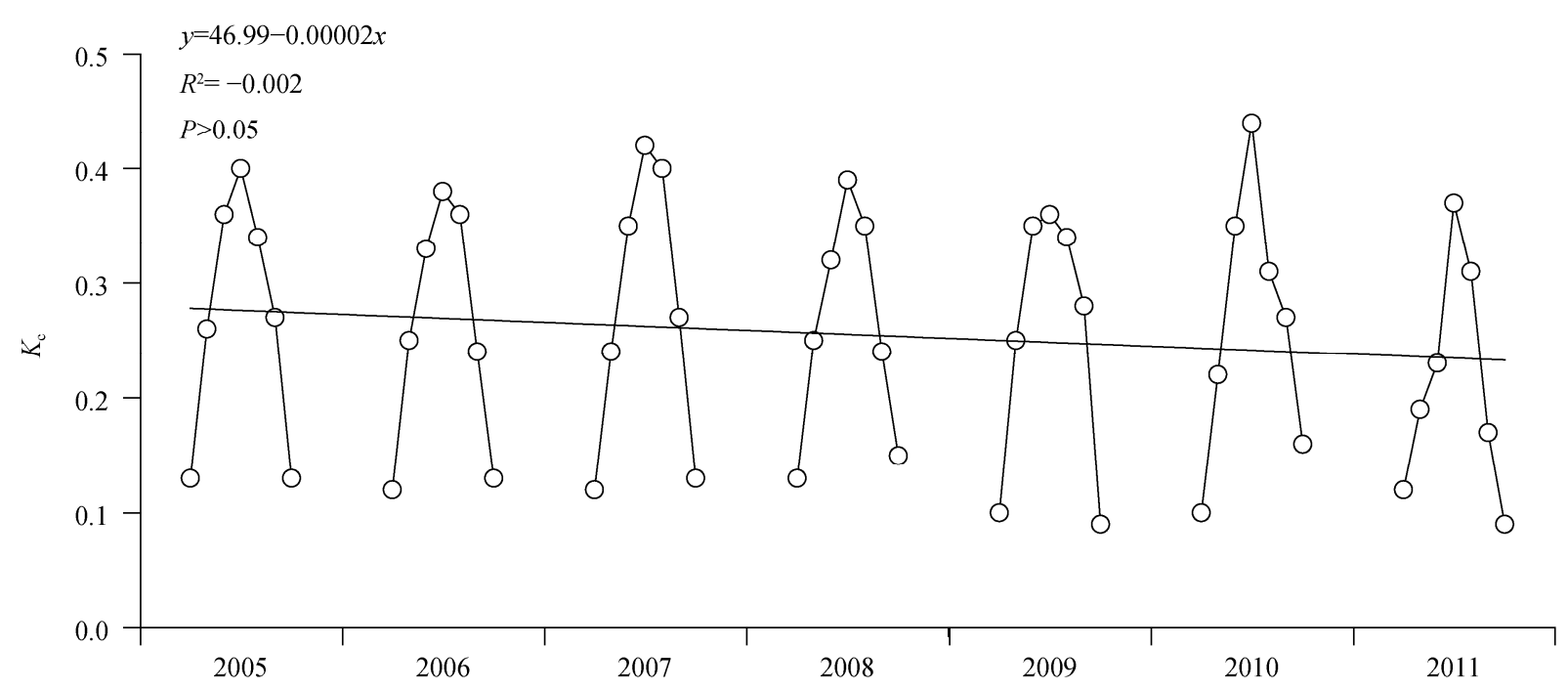

Fig. 6 Average monthly variation of $K_{\mathrm{c}}$ for the growing seasons from 2005 to 2011 

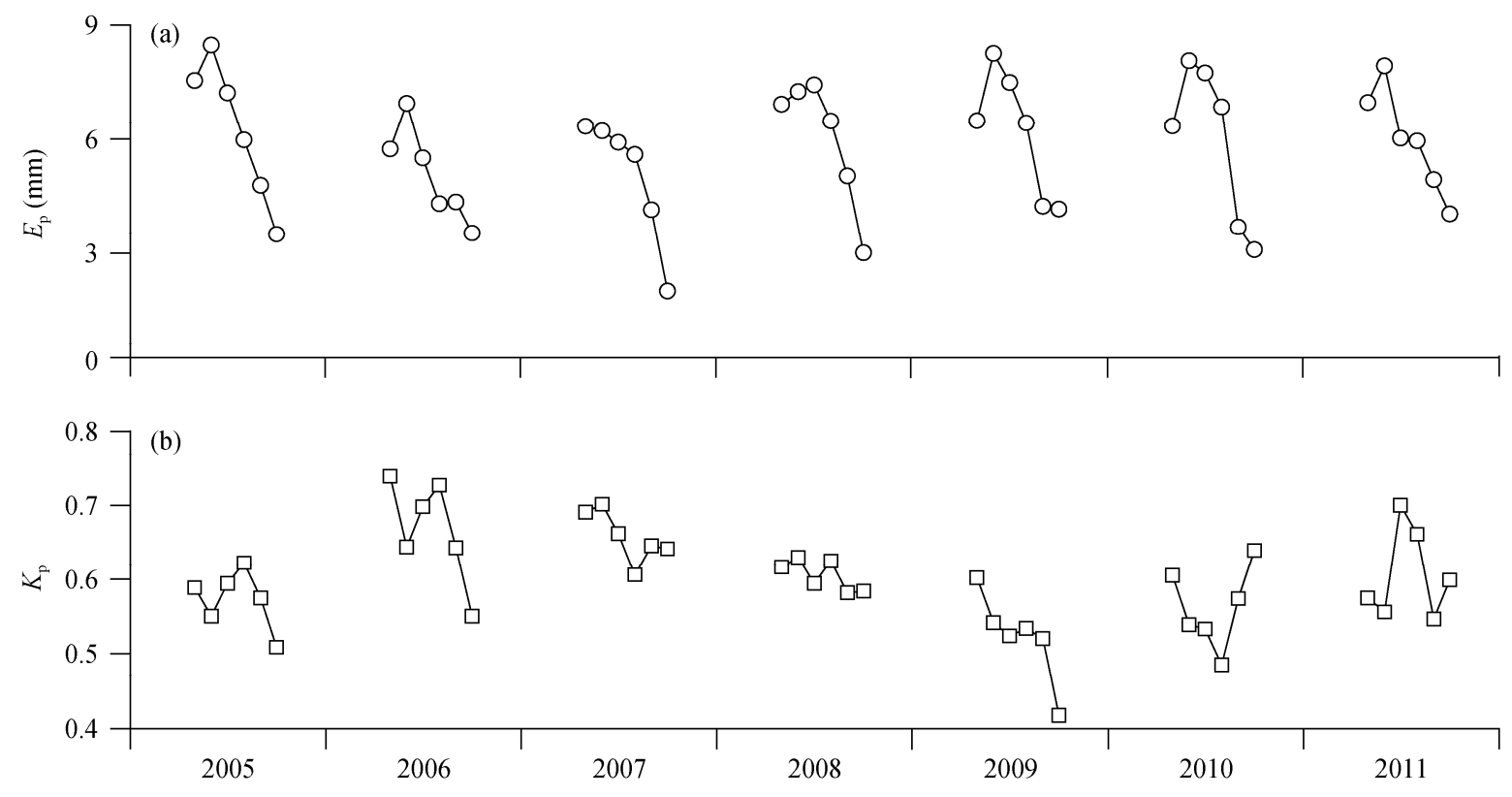

Fig. 7 Monthly variation of $E_{\mathrm{p}}$ and $K_{\mathrm{p}}$ for the growing seasons from 2005 to 2011

and Pruitt, 1984) is shown in the following:

$$
K_{\mathrm{p}}=0.482+a \ln (F)+b u_{2}+c R H .
$$

Where, $F$ is the upwind distance fetch of low-growing vegetation $(\mathrm{m}) ; u_{2}$ is the mean daily wind speed at $2 \mathrm{~m}$ $(\mathrm{mm} / \mathrm{d}) ; R H$ is the mean daily relative humidity $(\%)$; and $a, b$ and $c$ can be determined by curve fitting for different sites. This method has been developed and applied extensively (Cuenca, 1989; Snyder, 1992). According to Eq. 7 and the calculated values of $K_{\mathrm{p}}$ from Eq. 6, we can determined the three parameters and the equation related to $K_{\mathrm{p}}$ for the study area is as follows:

$$
\begin{aligned}
K_{\mathrm{p}}= & 0.482+0.050925 \ln (F)- \\
& 0.003216 u_{2}+0.013051 R H .
\end{aligned}
$$

As $K_{\mathrm{p}}$ and $E_{\mathrm{p}}$ can be easily obtained from only three meteorological parameters and an easy experiment, respectively, $E T_{0}$ can be found by using Eq. 8 in an area without sufficient meteorological parameters.

\section{Conclusions}

On the basis of the meteorological data, leaf area index of an oasis-desert transition zone in the middle stream of Heihe River from 2005 to 2011, this paper calculated $E T_{0}$ and $E T_{\mathrm{c}}$ according to the FAO56 P-M mode and P-M mode, respectively, and then $E T_{0}$ was verified by pan evaporation data.
The average value of $E T_{0}$ was $840 \mathrm{~mm} / \mathrm{a}$, while $E T_{\mathrm{c}}$ was $221 \mathrm{~mm} / \mathrm{a}$. Seasonal variations of $E T_{0}$ and $E T_{\mathrm{c}}$ were influenced by the meteorological parameters. The variation between $E T_{0}$ and $E T_{\mathrm{c}}$ was due to the differences in the influencing factors, while their common main influencing factors, i.e. net radiation and air temperature, were the causes for their similarity during the recording period. In addition, leaf area index is another important influencing factor of $E T_{\mathrm{c}}$.

When lacking full climatic data, paremater $K_{\mathrm{p}}$ is very important to predict $E T_{0}$ using observed $E_{\mathrm{p}}$. We put forward the emperical formula of $K_{\mathrm{p}}$ basing on Snyder equation, which was helpful to estimate $E T_{0}$ in this region.

According to the calculated $E T_{0}$ and $E T_{\text {c }}$, we obtained $K_{\mathrm{c}}$, with an average of about 0.2 . Little variation can be seen during the growing season, indicating that the oasis-desert transition zone had a balanced ecosystem. On the other hand, the mean annual $E T_{\mathrm{c}}$ was about $221 \mathrm{~mm}$. It is therefore suggested that available water of about $221 \mathrm{~mm}$ can maintain the water balance in the oasis-desert transition zone in the middle stream of the Heihe River.

\section{Acknowledgements}

This work was founded by the National Natural Science Foundation of China $(40930634,41125002)$. 


\section{References}

Allen R G, Smith M, Pereira L S, et al. 1994. An update for the calculation of reference evapotranspiration. ICID Bulletin, 43(2): 35-92.

Allen R G, Pereira L S, Raes D, et al. 1998. Crop evapotranspirationguidelines for computing crop water requirements-FAO Irrigation and drainage paper 56 . FAO, Rome.

Allen R G, Pereira L S, Howell T A, et al. 2011. Evapotranspiration information reporting: I. factors governing measurement accuracy. Agricultural Water Management, 98(6): 899-920.

ASCE-EWRI. 2005. The ASCE standardized reference evapotranspiration equation. In: Allen RG, Walter IA, Elliot RL, et al. Reported by the American Society of Civil Engineers (ASCE) Task Committee on Standardization of Reference Evapotranspiration. ASCE, Reston, 0-7844-0805-X, 204.

Brutsaert W, Parlange M B. 1998. Hydrologic cycle explains the evaporation paradox. Nature, 396(6706): 30.

Chiew F H S, Kamaladasa N N, Malano H M, et al. 1995. Penman-Monteith, FAO-24 reference crop evapotranspiration and class-A pan data in Australia. Agricultural Water Management, 28(1): 9-21.

Cuenca R H. 1989. Irrigation System Design: An Engineering Approach. Englewood Cliffs, NJ: Prentice Hall.

De La Fuente A, Bing N, Hoeschele I, et al. 2004. Discovery of meaningful associations in genomic data using partial correlation coefficients. Bioinformatics, 20(18): 3565-3574.

Doorenbos J, Pruitt W O. 1977. Crop water requirements. FAO Irrigation and Drainage. Paper 24. Land and Water Development Division, FAO, Rome.

Doorenbos J, Pruitt W O. 1984. Guidelines for predicting crop water requirements, Irrigation and Drainage Paper 24. Land and Water Development Division, FAO, Rome.

Ehlers E, Krafft T. 1996. German global change research. National Committee on Global Change Research, Bonn: 128.

Fisher J B, Whittaker R J, Malhi Y. 2011. ET come home: potential evapotranspiration in geographical ecology. Global Ecology and Biogeography, 20(1): 1-18.

Fu G, Liu C, Chen S, et al. 2004. Investigating the conversion coefficients for free water surface evaporation of different evaporation pans. Hydrological Processes, 18(2): 2247-2262.

Gao S, Su P X, Yan Q D, et al. 2010. Canopy and leaf gas exchange of Haloxylon ammodendron under different soil moisture regimes. Science China Life Sciences, 53(6): 718-728.

Howell T, Steiner J, Schneider A, et al. 1995. Evapotranspiration of irrigated winter wheat: Southern High Plains. Transactions of the ASAE, 38(3): 745-759.

Jensen D, Hargreaves G, Temesgen B, et al. 1997. Computation of $\mathrm{ET}_{0}$ under nonideal conditions. Journal of Irrigation and Drainage Engineering, 123(5): 394-400.

Jensen M E. 1974. Consumptive Use of Water and Irrigation Water Requirements. New York: American Society of Civil Engineers.

Jensen M E, Burman R D, Allen R G. 1990. Evapotranspiration and irrigation water requirements. ASCE.
Jia J H, Zhao W Z, Li S B. 2012. Regional evapotranspiration rate of oasis and surrounding desert. Hydrological Processes, doi: 10.1002/hyp.9447.

Li S B, Zhao W Z. 2010. Satellite-based actual evapotranspiration estimation in the middle reach of the Heihe River Basin using the SEBAL method. Hydrological Processes, 24(23): 3337-3344.

Li X M, Lu L, Yang W F, et al. 2011. Estimation of evapotranspiration in an arid region by remote sensing-A case study in the middle reaches of the Heihe River Basin. International Journal of Applied Earth Observation and Geoinformation, 17: 85-93.

Li Y, Horton R, Ren T, et al. 2010. Prediction of annual reference evapotranspiration using climatic data. Agricultural Water Management, 97(2): 300-308.

Liu B, Zhao W Z. 2009. Ecological adaptability of photosynthesis and water metabolism for Tamarix Ramosissima and Nitraria Sphaerocarpa in desert-oasis ecotone. Journal of Desert Research, 29(1): 101-107.

Liu B, Zhao W Z, Chang X X, et al. 2010. Water requirements and stability of oasis ecosystem in arid region, China. Environmental Earth Sciences, 59(6): 1235-1244.

Molina H P, Navarro A M, Osorio M R, et al. 2006. Social and irrigation water management issues in some water user's associations of the Low Segura River Valley (Alicante, Spain). Sustainable Irrigation Management, Technologies and Policies, 96: 205.

Monteith J L. 1965. Evaporation and Environment. In: Symposium of the Society of Experimental Biology. Cambridge, UK: Cambridge University Press, 205-234.

Monteith J L. 1981. Evaporation and surface temperature. Quarterly Journal of the Royal Meteorological Society, 107(451): 1-27.

Penman H L. 1948. Natural evaporation from open water, bare soil and grass. Proceedings of the Royal Society of London. Series A. Mathematical and Physical Sciences, 193(1032): 120-145.

Pereira L S, Perrier A, Allen R G, et al. 1999. Evapotranspiration: concepts and future trends. Journal of Irrigation and Drainage Engineering, 125(2): 45-51.

Priestley C, Taylor R. 1972. On the assessment of surface heat flux and evaporation using large-scale parameters. Monthly Weather Review, 100(2): 81-92.

Rana G, Katerji N. 2000. Measurement and estimation of actual evapotranspiration in the field under Mediterranean climate: a review. European Journal of Agronomy, 13(2): 125-153.

Raupach M. 2001. Combination theory and equilibrium evaporation. Quarterly Journal of the Royal Meteorological Society, 127(574): 1149-1181.

Shuttleworth W J, Wallace J. 1985. Evaporation from sparse crops-an energy combination theory. Quarterly Journal of the Royal Meteorological Society, 111(469): 839-855.

Snyder R L. 1992. Equation for evaporation pan to evapotranspiration conversions. Journal of Irrigation and Drainage Engineering, 118(6): 977-980.

Snyder R L, Orang M, Matyac S, et al. 2005. Simplified estimation of reference evapotranspiration from pan evaporation data in California. Journal of Irrigation and Drainage Engineering, 131(3): 249-253.

Stannard D I. 1993. Comparison of Penman-Monteith, 
Shuttleworth-Wallace, and modified Priestley-Taylor evapotranspiration models for wildland vegetation in semiarid rangeland. Water Resources Research, 29(5): 1379-1392.

Steiner J L, Howell T A, Schneider A D. 1991. Lysimetric evaluation of daily potential evapotranspiration models for grain sorghum. Agronomy Journal, 83(1): 240-247.

Su Y Z, Zhao W Z, Su P X, et al. 2007. Ecological effects of desertification control and desertified land reclamation in an oasis-desert ecotone in an arid region: a case study in Hexi Corridor, northwest China. Ecological Engineering, 29(2): 117-124.

Szeicz G, Long I. 1969. Surface resistance of crop canopies. Water Resources Research, 5(3): 622-633.

Tasumi M, Allen R G, Trezza R, et al. 2005. Satellite-based energy balance to assess within-population variance of crop coefficient curves. Journal of Irrigation and Drainage Engineering, 131(1): 94-109.

Thornthwaite C W. 1948. An approach toward a rational classification of climate. Geographical Review, 38(1): 55-94.

Verstraeten W W, Veroustraete F, Feyen J. 2008. Assessment of evapotranspiration and soil moisture content across different scales of observation. Sensors, 8(1): 70-117.

Wu J K, Ding Y J, Wei Z, et al. 2005. Study on the reference evapotranspiration of natural steppes in arid areas-a case study in the Middle Reaches of the Heihe River, Gansu Province. Arid Zone Research, 22(4): 514-519.

Xing Z, Chow L, Meng F, et al. 2008. Testing reference evapotranspiration estimation methods using evaporation pan and modeling in Maritime region of Canada. Journal of Irrigation and Drainage Engineering, 134(4): 417-424.

Xu C, Gong L, Jiang T, et al. 2006. Analysis of spatial distribution and temporal trend of reference evapotranspiration and pan evaporation in Changiiang (Yangtze River) catchment. Journal of Hydrology, 327(1): 81-93.

Zhang Y Q, Liu C M, Tang Y H, et al. 2007. Trends in pan evaporation and reference and actual evapotranspiration across the Tibetan Plateau. Journal of Geophysical Research, Atmospheres (1984-2012), 112(D12).

Zhao L W, Ji X B. 2010. Quantification of transpiration and evaporation over agricultural field using the FAO-56 dual crop coefficient approach-a case study of the maize field in an oasis in the middlestream of the Heihe River Basin in northwest China. China Agriculture Science, 43(19): 4016-4026.

Zhao W Z, Ji X B, Kang E S, et al. 2010a. Evaluation of Penman-Monteith model applied to a maize field in the arid area of northwest China. Hydrology and Earth System Sciences, 7(1): 461-491.

Zhao W Z, Liu B, Zhang Z H. 2010b. Water requirements of maize in the middle Heihe River basin, China. Agricultural Water Management, 97(2): 215-223.

Zhou L H, Yang G J. 2006. Ecological economic problems and development patterns of the Arid Inland River Basin in Northwest China. Ambio: 316-318. 